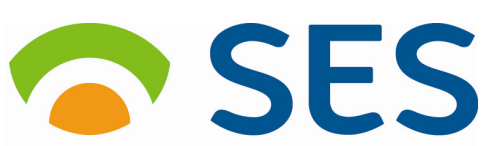

Sustainable Earth Sciences

\title{
Introduction
}

The Research Laboratory on Geological Storage of CO2 is located in Hontomín, about $30 \mathrm{~km}$ north to the city of Burgos (Spain) (figure 1). The area of study is a dome-like structure situated in the BasqueCantabrian Basin, and the main reservoir is a Natural Saline Aquifer with a thickness of more than $100 \mathrm{~m}$ and constituted by fractured and dolomitic limestones at $1500 \mathrm{~m}$ depth. The seals rocks belong to the overlying series of the Lias and Dogger, of which the main seal rocks are the marls and black shales.

Electrical and electromagnetic geophysical methods are sensitive to the electrical conductivity of pore fluid. The presence of $\mathrm{CO}_{2}$ inside the pore replaces a fraction of saline fluid within the storage aquifer, reducing the effective volume available for ionic transport. As a consequence, the bulk electrical resistivity of the rock increases significantly. Thus, the magnetotelluric method is a suitable geophysical technique to characterize the seal and reservoir units, and it is providing a baseline model for estimating the $\mathrm{CO}_{2}$ plume distribution afterwards the injection.

Here, we present the preliminary results of the electromagnetic characterization that has been carried out in the Research Laboratory of Hontomín. The survey was divided into two stages: a two dimensional (2-D) acquisition that took place in spring 2010 and a three dimensional (3-D) acquisition, in autumn 2010. The 2-D acquisition (MTD profile) helped to design the 3-D survey as well as provided the first geoelectric image of the study area. In the same way, the preliminary 3-D resistivity model provides the geoelectric baseline model of the Research Laboratory $\left(3 \times 4 \mathrm{~km}^{2}\right)$.

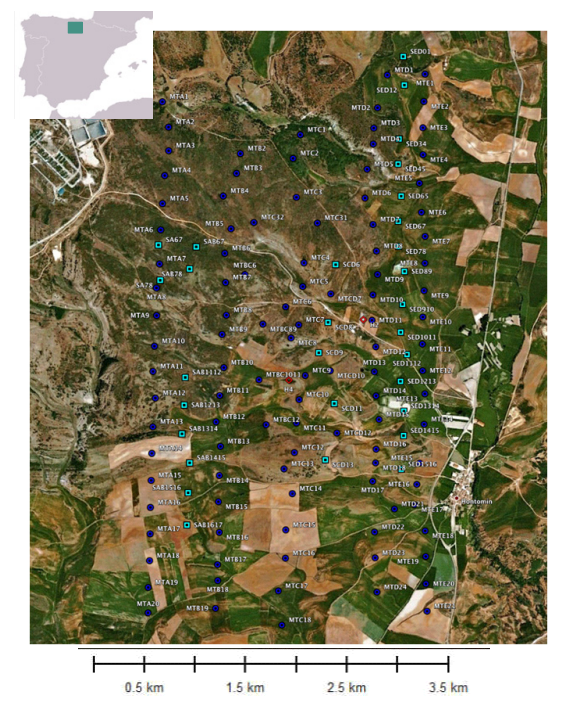

Figure 1: Location of the Research Laboratory on Geological Storage of $\mathrm{CO}_{2}$ in Hontomin (Burgos, Spain). Circles represent the location of broadband magnetotelluric sites. MTD profile corresponds to the 2-D acquisition (spring 2010). In red, two of the wells of the study area (Hontomin-2 and Hontomin-4).

\section{Methodology and Results}

The magnetotelluric method (MT) is a natural-source electromagnetic technique that make possible to infer the electrical conductivity distribution of the subsurface by measuring simultaneously the temporal fluctuations of the horizontal components of the natural electromagnetic field (Vozoff, 1991).

$1^{\text {st }}$ Sustainable Earth Sciences Conference \& Exhibition -

Technologies for Sustainable Use of the Deep Sub-surface

8-11 November 2011, Valencia, Spain 


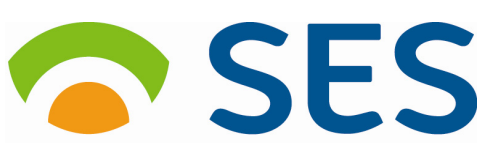

Sustainable Earth Sciences

In total, 109 broadband MT (BBMT) sounding have been acquired mainly along five north-south profiles of around $4 \mathrm{~km}$ long in the period range of $15 \mathrm{~Hz}$ to $4096 \mathrm{~Hz}$. The stations were deployed at roughly $200 \mathrm{~m}$ intervals, recording data during 24 to 48 hours, and the average distance between profiles was $500 \mathrm{~m}$ (figure 1). The instrumentation consisted of Metronix ADU06, Metronix ADU07 and Phoenix V8. A remote reference station was permanently placed around $20 \mathrm{~km}$ away from study area. Different robust processing codes using remote reference methods have been tested and used at all stations of the profile to derive optimal MT responses.

For the 2-D characterization (MTD profile), MT data at each site have been decomposed using the STRIKE code of McNeice and Jones (2001), which is based on the method of Groom and Bailey (1989), in order to model the best geoelectrical strike direction. The results confirm that all MT responses along the profile are consistent with a 2-D assumption and therefore, suitable for 2-D modelling.

The 2-D electrical resistivity model of the subsurface has been computed by 2-D simultaneous smooth inversion of all the MT responses along the profile. The inversion method used is that of Rodi and Mackie (2001). Figure 2 shows the comparison between data and model responses for apparent resistivities and phases of TE and TM modes.
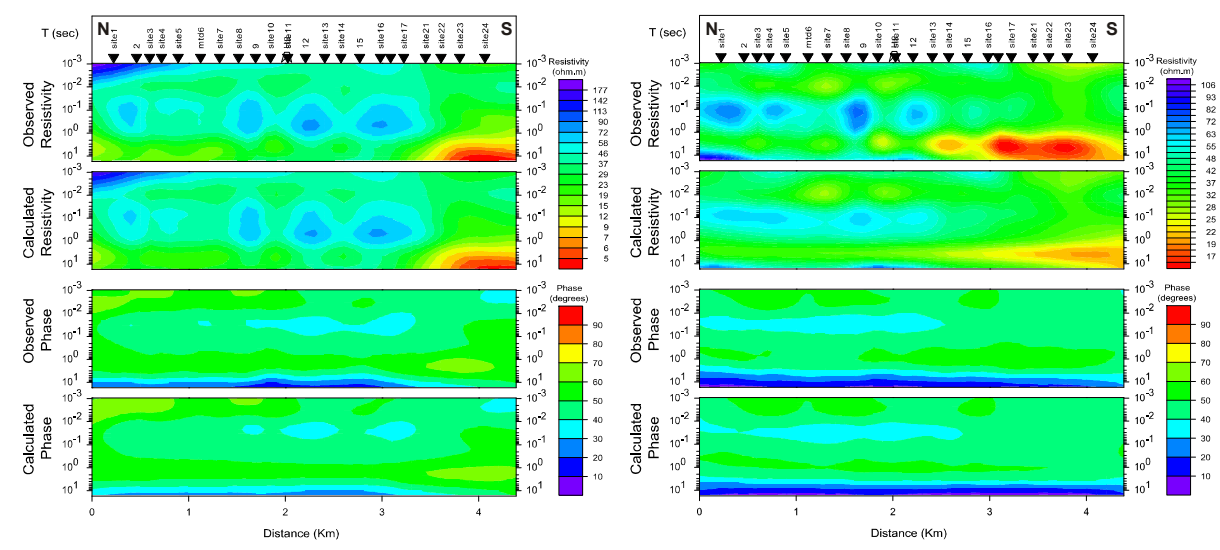

Figure 2: 2D resistivity model (MTD profile) pseudo-sections -apparent resistivity and phases measured and model responses-Left TM mode, right TE mode.

\section{Conclusions}

The obtained 2-D MT resistivity model shows a clear correlation between the model and the resistivity data provided by exploration well Hontomín-2 situated close to the centre of the profile. The preliminary 3-D geoelectric model constitutes the baseline model of the Research Laboratory. It confirms the results provided by the 2-D model as well as adds new information about the geoelectric structure of the study area.

The seal rocks are clearly associated to a resistive body while the reservoir is associated to the conductive body situated underneath. The model highlights an important fluid circulation along a fault located in Upper Jurassic-Lower Cretaceous materials, in the southern part. 


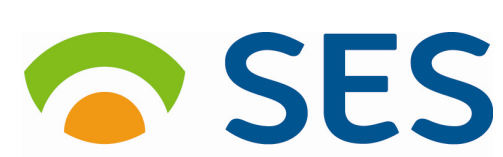

Sustainable Earth Sciences

\section{Acknowledgements}

Xènia Ogaya is being currently supported by the Fundación Ciudad de la Energía (CIUDEN) Research training program. This research was funded by the CIUDEN and the PIER-CO2 Project (CGL2009-07604).

\section{References}

Groom, R.W. and Bailey, R.C. [1989] Decomposition of magnetotelluric impedance tensors in the presence of local three-dimensional galvanic distortion. J. Geophys. Res., 94, 1913-1925.

McNeice, G.W. and Jones, A.G. [2001] Multisite, multifrequency tensor decomposition of magnetotelluric data. Geophysics, 66(1), 158-173.

Rodi, W. and Mackie, R.L. [2001] Non linear conjugate gradients algorithm for 2D magnetotelluric inversion. Geophysics, 66, 174-187.

Vozoff, K. [1991] The magnetotelluric method. In: Nabighian, M.N. (Ed.), Electromagnetic Methods in Applied Geophysics, vol. 2B. Soc. Explor. Geophysics, Tulsa, OK, USA, 641-711. 